\title{
Should an athlete eat straight after training? - a study of intestinal transit time and its relationship to prior exercise
}

\author{
Duncan Scott and Brian Scott* MD FRCP \\ Department of Sport and Leisure Studies, North Lincolnshire College and *Department of Gastroenterology, \\ County Hospital, Lincoln, UK
}

\begin{abstract}
The mouth-to-caecum transit time of food was measured using the rise in breath hydrogen after a standard breakfast of baked beans on two occasions in seven healthy volunteers. The first occasion was after resting and the second after moderate exercise on a bicycle ergometer. There was no significant difference between the transit times with or without prior exercise. It is concluded that moderate exercise taken before food does not interfere with transit time and therefore should not in that way interfere with nutrition.
\end{abstract}

Keywords: Intestinal transit time, exercise, breath hydrogen test

There is currently considerable interest in nutrition among athletes. There is much expenditure on nutritious foods to improve performance. However, these same athletes train frequently and therefore it would be important to know whether absorption of a meal might be jeopardized by the prior exercise.

Digestion and absorption of food starts when food enters the mouth and continues until it reaches the caecum. The time food takes to pass from the mouth to the caecum could affect how much nutrient is absorbed. If this time is reduced then nutrition could be impaired. The mouth-to-caecum transit time can be measured simply using breath hydrogen measurements. This depends upon the fact that not all dietary carbohydrate is digested and absorbed. Some will therefore reach the caecum, where there are bacteria which break down the non-absorbed carbohydrate to hydrogen. Some of this hydrogen is absorbed into the blood stream, goes to the lungs, and is promptly excreted in the breath. It is possible to measure the hydrogen concentration in the breath easily using a direct-reading hydrogen monitor. Thus, by making sure there is indigestible carbohydrate in a meal, it is possible to measure the mouth-to-caecum transit time by taking the time for the level of hydrogen in the breath to rise. Of course this time to rise reflects the time for the arrival of the first part of the meal. The time for the peak rise in breath hydrogen is also used,

Address for correspondence: Dr Brian Scott, County Hospital, Lincoln LN2 5QY, UK

(C) 1994 Butterworth-Heinemann Ltd 0306-3674/94/010022-03 which might be expected to reflect the mean transit for the whole meal, although this has not been confirmed.

The measurement of mouth-to-caecum transit time using breath hydrogen was first reported by Bond and Levitt in $1975^{1}$. They used the liquid sugar, lactulose, instead of a meal because this sugar cannot be digested by humans. Most other studies have used the same technique. Unfortunately, taking lactulose, which is also used as a laxative, is unphysiological and very different from taking normal food and may not be so meaningful. Read and his colleagues in $1980^{2}$ showed that an ordinary meal containing baked beans could be used to measure the mouth-to-caecum transit time because baked beans contain two indigestible sugars, stachyose and raffinose. The meal they used contained precise amounts of potato, sausages, pineapple and custard. Using their meal the transit time was approximately $4 \mathrm{~h} 30 \mathrm{~min}$ compared with $1 \mathrm{~h} 30 \mathrm{~min}$ using artificial lactulose. There was excellent correlation between the transit time obtained in this way and that obtained by timing the arrival of radioactive markers at the right iliac fossa. All other breath hydrogen studies of transit time seem to have used lactulose.

There have already been many studies looking at the relationship between exercise and intestinal transit time. Cordain and colleagues ${ }^{3}$ showed, using a carmine red marker, that a 6-week training programme accelerated whole gut transit. This was confirmed by Koffler and colleagues ${ }^{4}$ using radiopaque markers but they found no effect on mouth-tocaecum transit time. Bingham and Cummings ${ }^{5}$, using the same technique, found no consistent effect of a fitness training programme on large bowel transit. Ollerenshaw and colleagues ${ }^{6}$, using radiolabelled particles, showed slight slowing of small intestinal transit during moderate activity and slight acceleration during strenuous activity. Using the lactulose breath test, Keeling and colleagues showed acceleration of mouth-to-caecum transit during mild exercise in both men ${ }^{7}$ and women ${ }^{8}$, whereas Meshkinpour and colleagues ${ }^{9}$ showed slowing of transit during mild exercise using the same technique. Soffer and colleagues ${ }^{10}$ showed no effect on mouth-to-caecum transit time of intense exercise taken after a meal, also using the lactulose breath hydrogen test. No study 
has looked at the effect of prior exercise on mouth-to-caecum transit time. The purpose of this study was to investigate the effect of moderate prior exercise on mouth-to-caecum transit using breath hydrogen measurements after a normal meal without lactulose.

\section{Subjects and methods}

There were seven volunteers. Four were men. The mean age was 23 years with a range of 18 to 47 years. They were all healthy with no diarrhoea or suggestion of malabsorption. Two were trained track athletes.

\section{Measurement of breath hydrogen}

End-expiratory breath samples were collected into a plastic syringe every $15 \mathrm{~min}$ for $5 \mathrm{~h}$ after the meal, during which the subjects remained indoors, mainly sitting down. The samples were analysed immediately using an electrochemical cell (Exhaled Hydrogen Monitor, GMI Medical, Renfrew, Scotland). Hydrogen concentration was expressed in p.p.m. (parts per million).

\section{The meal}

The standard breakfast consisted of $225 \mathrm{~g}$ baked beans, two slices of toast, a glass of orange juice, two biscuits and a cup of tea. This was eaten in less than $15 \mathrm{~min}$. This meal was taken at 08.30 hours and the subjects were asked not to eat anything after 20.00 hours the previous night. In pilot studies this was found to be simple, acceptable and measurable. In two subjects repeat tests showed the 'time to rise' of breath hydrogen on different days varied by only $15 \mathrm{~min}$ and $45 \mathrm{~min}$. This is reasonable reproducibility given the normal range for the test of 1.25 to $4.0 \mathrm{~h}$ obtained from ten controls.

\section{The exercise}

The subjects exercised on a bicycle ergometer at a fixed speed and resistance. The heart rate was recorded every minute using an attached electrocardiograph monitor. If after $4 \mathrm{~min}$ the heart rate had not reached $75 \%$ above basal the resistance setting was increased by one setting every minute until the heart rate reached $75 \%$ above basal. The setting was then left unchanged. The heart rate of all subjects exceeded 150 per minute. The exercise continued for a total of $10 \mathrm{~min}$. The standard breakfast was eaten $20 \mathrm{~min}$ after the end of the exercise.

\section{Measurement of transit time}

Two measurement periods were designated for statistical comparison. One, the 'time to rise', was from the start of the meal to the rise in breath hydrogen. This was the time when the reading became higher by more than 1 p.p.m. than any other in the previous hour and which also remained higher in the next hour. The other, the 'time to peak', was from the start of the meal to the peak hydrogen reading. A typical test would give a resting breath hydrogen of 5 p.p.m. and a peak reading of 35 p.p.m.

\section{Statistics}

For comparing means the Student's $t$ test was used. However, because it had not been determined whether or not mouth-to-caecum transit times follow a normal distribution the non-parametric Wilcoxon rank sum test was also used.

\section{Results}

The mouth-to-caecum times with and without prior exercise for each subject are shown in Figures 1 and 2. In Figure 1 the 'time to rise' is used and in Figure 2 the 'time to peak' is used. There was no significant effect of prior exercise on either measurement. The mean 'time to rise' without exercise and after exercise was $2.79 \mathrm{~h}$ and $2.85 \mathrm{~h}$ respectively $(P>0.05)$. The mean 'time to peak' without and with exercise was $4.13 \mathrm{~h}$ and $4.18 \mathrm{~h}$ respectively $(P>0.05)$. No difference between the men and women was seen in the response to prior exercise.

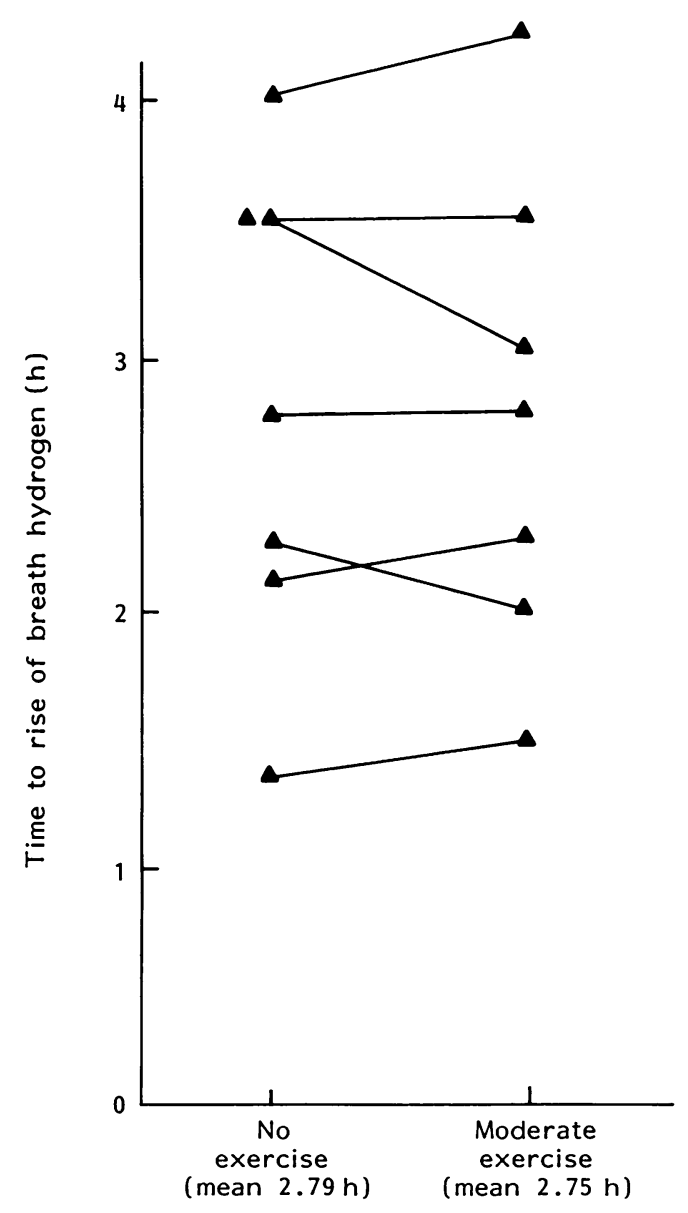

Figure 1. The time to rise of breath hydrogen (h) after the standard meal, with and without prior exercise, in seven subjects 


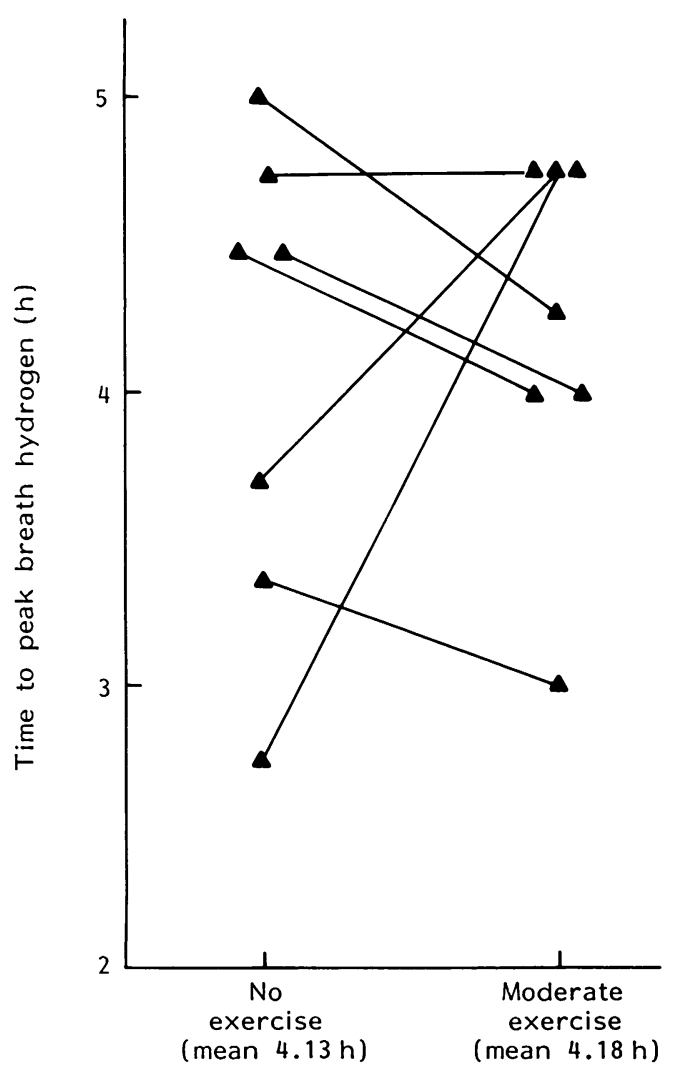

Figure 2. The time to peak of breath hydrogen (h) after the standard meal, with and without prior exercise, in seven subjects

\section{Discussion}

This study has shown that there is no significant difference in the mouth-to-caecum transit time of a standard meal whether or not moderate exercise is taken $20 \mathrm{~min}$ previously. It therefore seems likely that as far as nutrition is concerned it is satisfactory for an athlete to eat as soon after training as he feels like it. Indeed, there may be an actual advantage in re-supplying carbohydrate as soon as possible after glycogen-depleting exercise since the rate of glycogen synthesis is quickest in the first couple of hours after exercise $^{11}$. Of course, athletes' training sessions vary in duration and intensity and this study could be repeated using even more prolonged and strenuous exercise. It is still possible that absorption of food is impaired by prior exercise by some other mechanism. For instance, during strenuous exercise blood is diverted from the intestine to the working muscles. The possibility therefore exists that the blood supply remains reduced for a while even after the exercise is completed resulting in a reduction in absorption, even though transit is not affected. This could be tested using the xylose absorption test with and without prior exercise.

\section{References}

1 Bond JH, Levitt MD. Investigation of small bowel transit time in man using pulmonary hydrogen measurements. J Lab Clin Med 1975; 85: 546-55.

2. Read NW, Miles CA, Fisher D, Holgate AM et al. Transit of a meal through the stomach, small intestine and colon in normal subjects and its role in the pathogenesis of diarrhoea. Gastroenterology 1980; 79: 1276-82.

3 Cordain L, Latin RW, Behnke JJ. The effects of an aerobic running program on bowel transit time. J Sports Med 1986; 26: 101-4.

4 Koffler KH, Menkes A, Redmond RA, Whitehead WE, Pratley RE, Hurley BF. Strength training accelerates gastrointestinal transit in middle-aged and older men. Med Sci Sports Exerc 1992; 24: 415-9.

5 Bingham SA, Cummings JH. Effect of exercise and physical fitness on large intestinal function. Gastroenterology 1989; 97: 1389-99.

6 Ollerenshaw KJ, Norman S, Wilson CG, Hardy JG. Exercise and small intestinal transit. Nuc Med Comm 1987; 8: 105-10.

7 Keeling WF, Martin B. Gastrointestinal transit during mild exercise. J Appl Physiol 1987; 63: 978-81.

8 Keeling WF, Harris A, Martin BJ. Orocecal transit during mild exercise in women. J Appl Physiol 1990; 68: 1350-3.

9 Meshinkpour H, Kemp C, Fairshter R. Effect of aerobic exercise on mouth-to-caecum transit time. Gastroenterology 1989; 96: 938-41.

10 Soffer EE, Summers RW, Gisolfi C. Effect of exercise on intestinal motility and transit in trained athletes. Am J Physiol 1991; 260: G698-702.

11 Costill DL, Sherman WM, Fink WJ, Maresh C, Witten M, Miller JM. The role of dietary carbohydrates in muscle glycogen resynthesis after strenuous running. Am J Clin Nutr 1981; 34: 1831-6. 